\title{
AS DESIGNAÇÕES DE "HISTÓRIA" E "TEMPO” NO LIVRO DIDÁTICO DE HISTÓRIA, SOCIEDADE \& CIDADANIA (6 ANO) NA PERSPECTIVA DA SEMÂNTICA DO ACONTECIMENTO
}

\author{
ALEXANDRE MACEDO PEREIRA (UFPB) ${ }^{1}$ \\ http://orcid.org/0000-0001-7093-582X \\ MÔNICA MANO TRINDADE FERRAZ (UFPB) $)^{2}$ \\ http://orcid.org/0000-0003-1265-8590
}

\begin{abstract}
RESUMO: O mundo contemporâneo é um espaço organizado e normatizado pela modalidade escrita da língua. Nesse cenário, a escola pública brasileira organiza suas atividades de ensino a partir do Livro Didático (LD) e, em alguns casos, este é o único recurso didático disponível na escola. Este trabalho tem como objetivo analisar as designações dos termos "história" e "tempo", no LD de História intitulado Sociedade \& Cidadania do $6^{\circ}$ ano (BOULOS JUNIOR, 2015), a partir dos postulados teórico-metodológicos da Semântica do Acontecimento, discutindo a relevância desses conceitos no processo de ensino-aprendizagem desta disciplina. Teoricamente, fundamenta-se nas obras Guimarães (2017) e Rancière (2018), Marx (2011), Marx (2013), Koselleck (2014). Na análise, identificamos que a designação de "história", no enunciado [1], significa ultrapassado e desinteressante; no enunciado [2], significa prazer e conhecimento. A designação de "tempo", no enunciado [3], significa período contínuo de caráter natural ou mecânico; no enunciado [4], significa período contínuo de caráter coletivo (cultural). Por fim, é possível concluir que a articulação da Semântica do Acontecimento com a disciplina História pode potencializar a aprendizagem, uma vez que pode ampliar a percepção dos alunos quanto à dinâmica dos fenômenos históricos.
\end{abstract}

PALAVRAS-CHAVE: Semântica. Semântica do Acontecimento. Ensino de História.

ABSTRACT: Contemporary world is a place organized and ruled by the written form of the language. In this scenario, Brazilian public schools arrange their teaching activities having the Didactic Book (DB) as a primary resource and, in some cases, the only resource available at schools. Taking into consideration the theoretical, methodological assumptions of the Semantics of the Event, this work aims to analyze the designation of the terms "History" and "Time", in a History didactic book entitled "Sociedade e Cidadania", written by Boulos Junior (2015), and assigned for sixth grade students of Brazilian Educational System, by discussing the relevance of those assumptions in the teachinglearning process of this school subject. This article is a result of a research which methodology was bibliographic, qualitative and exploratory. As regards to its theoretical support, we have used the works of Guimarães (2017) and Rancière (2018). Going through the analysis, it was identified that the designation of "History", in statement [1], means something outdated and uninteresting. In statement [2], however, "History" means pleasure and knowledge. As for the designation of "Time" in statement [3], it means a natural or mechanic ongoing period. Although, in statement [4], it means collective (cultural) ongoing period. Finally, it is possible to conclude that articulation of the Semantics of the Event with the discipline History can enhance learning, since it can increase the students' perception of the dynamics of historical phenomena.

KEYWORDS: Semantics. Semantics of the Event. History teaching.

\footnotetext{
1 Pós-doutor em Linguística (PROLING/UFPB), Doutor em Educação - área Educação Ambiental (PPGEA/FURG). Professor da Universidade Federal da Paraíba (UFPB), vinculado ao Departamento de Habilitações Pedagógicas (DHP), Centro de Educação (CE). E-mail: alexandremacedopereira@gmail.com

2 Doutora em Linguística Teórica pela Universidade Federal de Santa Catarina (2006). Professora da Universidade Federal da Paraíba. Tem experiência na área de Língua Portuguesa e Linguística, com ênfase em Semântica, Linguística Textual e Metodologia de Ensino. E-mail: monicatrin@hotmail.com
} 


\section{$=$ TRAMA $=$}

\section{INTRODUÇÃO}

A humanidade, na contemporaneidade, experiencia um momento singular no que concerne à integração entre as pessoas. Nas últimas décadas e, em particular, na atualidade, as relações humanas vêm sendo transformadas em ritmo acelerado pela revolução tecnológica, sobretudo com o advento da rede global de comunicação (a internet) e o surgimento de novos Apps de comunicação e serviços.

Esses novos mecanismos tecnológicos aceleram as comunicações entre as pessoas e instituições, potencializam a produção e a socialização de conhecimentos, dinamizam as relações entre grupos sociais e criam redes de compartilhamento de informações. Em tese, as tecnologias, em particular, a internet, configuram-se como um espaço de integração e interação.

Nesse cenário dinâmico e complexo, a educação formal, sobretudo a educação pública brasileira, vê-se diante de um dilema: desenvolver uma proposta didático-pedagógica integradora, capaz de responder às necessidades próprias do momento histórico em curso, objetivando a formação eficiente e eficaz dos educandos, ou manter-se atrelada a um modelo didático-pedagógico conservador reprodutivista. Sabe-se que o momento histórico atual não admite modelos educacionais (pedagógicos e administrativos) compartimentados e fragmentados. O dinamismo do mundo contemporâneo exige processos educacionais interconectados, vinculados a uma visão integradora de sociedade. Nesse modelo societal, a escola, na condição de instituição responsável pela formação dos educandos, tem o desafio de desenvolver propostas didático-pedagógicos capazes de articular a integração entre áreas distintas do conhecimento e potencializar o processo de aprendizagem dos educandos, considerando as condições histórico-sociais existentes (PIMENTA, s/d). Trata-se, então, de pensar em uma educação que, na sua essência, prime pela qualidade da formação dos educandos (SAVIANI, 2015).

Considerando esse cenário e as atuais exigências da sociedade contemporânea, os Parâmetros Curriculares Nacionais-PCNs (2000) orientam os sistemas públicos educacionais (municipal, estadual e federal) a desenvolverem programas didático-pedagógicos que fomentem a formação interdisciplinar (ação integradora entre áreas distintas do conhecimento). Segundo os PCNs, os currículos escolares devem: a) estar conectados com as demandas da sociedade local, regional e global; b) integrar áreas distintas do conhecimento; e c) fomentar uma educação cidadã.

Entre o idealizado pelos PCNs (2000) e a realidade da educação, em particular a pública no Brasil, há uma lacuna que se apresenta como intransponível. No cotidiano das escolas brasileiras, a integração de conhecimentos como prática didático-pedagógica a serviço da aprendizagem não vem sendo efetivada (salvo raras exceções).

No que se refere à disciplina de História, normalmente privilegia-se o ensino dos fatos históricos. Notadamente, o ensino de história nas escolas brasileiras dá preferência a práticas didático-pedagógicas endógenas, ignorando, assim, as possibilidades de integração com outras áreas do conhecimento, como, por exemplo, a relação entre os estudos da Linguagem e a História. Vale ressaltar que, em sua ampla maioria, as pesquisas no campo da História dãose a partir de fontes escritas (documentos, cartas, relatórios etc.) e orais (relatos, histórias, contos etc.). É significativo registrar também que o ensino dessa disciplina nas escolas brasileiras, em geral, é realizado a partir de materiais didáticos escritos. Considerando a importância da escrita para a pesquisa e para o ensino de História, pode-se tomar como hipótese que a integração entre essas áreas - linguagem e história - contribua com o processo de ensino-aprendizagem. Ao tratarmos dos estudos concernentes à linguagem, delimitamo-nos aqui aos aspectos da significação, o que define a Semântica como nosso aporte teórico e, de 


\section{$=$ TRAMA $=$}

modo bem específico, elegemos a Semântica do Acontecimento. Defendemos, portanto, que não integrar a Semântica ao ensino de História pode limitar as possibilidades de aprendizagem dos educandos em relação ao fenômeno em estudo, pois as percepções e as apreensões sobre o conteúdo conceitual requerem a compreensão dos sentidos designados nas enunciações de nomes e expressões linguísticas. Essa compreensão é possibilitada por meio da articulação entre a Semântica e o ensino de História.

No caso da educação brasileira, o Livro Didático (LD) é o principal recurso didáticopedagógico (salvo exceções) disponível aos discentes e docentes. O LD é um espaço dominado pela escrita, sobretudo pela escrita na norma culta. É importante ressaltar que o LD de história é um espaço constituído de palavras, enunciados e textos, frutos de enunciações carregadas de sentidos, e, se abordados a partir de uma perspectiva didático-pedagógica integradora (interdisciplinar), articulando Semântica e História, podem potencializar ainda mais a aprendizagem dos alunos. Assim, este trabalho defende a tese de que a articulação do componente curricular História com a Semântica do Acontecimento contribui para os processos de ensino-aprendizagem. A abordagem dos fenômenos históricos a partir dos sentidos das designações (Semântica do Acontecimento) fornece aos educadores e educandos outras formas de abordar um mesmo fenômeno, permitindo que esses sujeitos percebam as designações como elementos de sentidos.

O LD de história como lugar de palavras, enunciados e textos, frutos de enunciações, é um espaço de acontecimentos, e tal espaço é marcado pela relação língua/falantes. É importante destacar que a relação língua/falante é uma relação de disputas pela palavra e pelas línguas, pois o espaço da língua é também um espaço político (GUIMARÃES, 2005). De acordo com Guimarães (2005, p.18), "a língua é dividida no sentido de que ela é necessariamente atravessada pela política: ela é normativamente dividida e é também a condição de para se afirmar o pertencimento dos não incluídos, a igualdade dos desigualmente divididos". Assim, é importante ressaltar que o LD de história como espaço da língua constitui o falante como agente político. Desse modo, entende-se ser relevante estudar a semântica enquanto elemento didático-pedagógico aplicada ao ensino de História.

O processo de narrativa, análise e descrição da história dá-se a partir de escolhas nem sempre conscientes, determinadas por acontecimentos políticos, ideológicos, sociais e culturais, que se manifestam, direta e/ou indiretamente, na língua. Assim, analisar os elementos linguísticos presentes no LD de história possibilita o desenvolvimento de uma compreensão ampla sobre os fenômenos em estudo.

Este estudo é relevante também porque permite pensar a integração entre diferentes áreas do conhecimento, contribuindo, dessa forma, para a efetivação da interdisciplinaridade no campo da educação. A inserção da Semântica do Acontecimento no corpus das metodologias de ensino nas diversas áreas do conhecimento e, em especial, no ensino de História, possibilitará a ampliação do desenvolvimento crítico-reflexivo dos alunos.

Este artigo objetiva: a) analisar as designações "história" e "tempo", no LD História, Sociedade \& Cidadania do $6^{\circ}$ ano, disponibilizado pelo governo federal, através do Programa Nacional do Livro Didático (PNLD); b) apresentar a contribuição possível da articulação da Semântica do Acontecimento com a disciplina História no processo de ensino-aprendizagem da disciplina História.

Pesquisar é sempre um processo complexo. Definir os instrumentos de pesquisa e o aporte teórico que sustentará a pesquisa não é apenas uma escolha subjetiva. Assim, esse processo é resultado de uma relação profunda do pesquisador com o fenômeno, na qual a relação sujeito/objeto é dialética, ou seja, uma relação em que a realidade objetiva organiza o sujeito. Segundo Tonet (2013, p. 109), "ser objetivo é capturar a lógica própria do objeto". 


\section{$=$ TRAMA $=$}

Nesse sentido, compreendemos a práxis teórica como o processo em que a consciência (mediadora), em uma relação metabólica com a realidade transforma essa realidade em ideias.

Assim, o pressuposto teórico metodológico desta pesquisa é a dialética materialista. O método na pesquisa dialética materialista é um processo constituído de duas etapas: investigação e exposição (MARX, 2013). A investigação, nessa perspectiva, dá-se à medida que o pesquisador se apropria da matéria na riqueza de seus detalhes, isto é, à medida que o pesquisador analisa os múltiplos movimentos do desenvolvimento da pesquisa, sem perder o foco dos nexos externos. Após esse processo, o resultado da pesquisa deve ser anunciado.

Esta é uma pesquisa exploratória, bibliográfica e de caráter qualitativo. Importante ressaltar que o caráter qualitativo da pesquisa não ignora a relação indissociável entre qualidade/quantidade.

\section{AS PALAVRAS E OS SENTIDOS: O DESAFIO DO(S) SEMANTICISTA(S)}

Investigar o sentido das palavras, expressões e enunciados tem sido alvo de qualquer linha teórica da semântica, bem como também há uma busca pela definição dos termos significado, sentido e significação por parte dos semanticistas. Assim, mesmo sendo consensual entre os estudiosos da área que o objeto de estudo da semântica é o significado, a definição de significado diverge entre as correntes.

Bréal (1992), considerado o fundador da semântica moderna com a publicação de Ensaio de Semântica na virada do século XIX para o século XX, já discutia o significado das palavras, abordando as relações dadas no léxico, os processos de nomeação e de designação. Ao refletir sobre o modo como as coisas são nomeadas, chama a atenção para a instabilidade e a não completude dessa relação. Segundo o autor,

De tudo o que precede podemos tirar uma conclusão: não há dúvida de que a linguagem designa as coisas de modo incompleto e inexato. Incompleto, porque não se esgotou tudo o que se pode dizer do sol quando se disse que ele brilha, ou do cavalo quando se disse que ele corre. Inexato, porque não se pode dizer do sol que ele brilha quando se escondeu, ou do cavalo que ele corre quando está em repouso, ou quando está ferido ou morto (BRÉAL, 1992, p.123).

Ainda no caminho de explicar tal incompletude, Bréal (1992) diferencia o processo de nomeação dos objetos concretos do processo de nomeação daquilo que é abstrato. No primeiro caso, há sempre um recorte a ser feito, pois o objeto, enquanto coisa existente no mundo, abarca noções mais amplas das que a palavra que o nomeia é capaz de captar. Assim, o autor afirma que:

[...] os substantivos são signos ligados às coisas: eles encerram exatamente a parte da verdade que um nome pode encerrar, parte necessariamente tão menor quanto mais tem de realidade o objeto. O que há em nossas línguas, de mais adequado ao objeto, são os nomes abstratos, pois representam uma simples operação do espírito. Quando tomo as duas palavras, compressibilité (compressibilidade), immortalité (imortalidade, imortal, viver para sempre), tudo o que se acha na ideia se acha na palavra. Mas, se tomo um ser real, um objeto existente na natureza, será impossível a linguagem fazer entrar na palavra todas as noções que esse ser ou esse objeto desperta no espírito. A linguagem é obrigada a escolher. Entre todas as noções, a linguagem escolhe apenas uma: cria assim uma: cria assim um nome que não tarda a se tornar um signo (BRÉAL, 1992, p.123).

Na concepção de Bréal (1992), a palavra e as coisas têm uma relação, mas, dada a complexidade das coisas, as palavras só podem expressar característica parcial das coisas. Podemos, então, inferir que as palavras, segundo Bréal (1992), manifestam apenas o sentido 


\section{$=$ TRAMA $=$}

parcial das coisas. A completude do sentido, na concepção do referido autor, só ocorre na relação da ideia com a palavra, pois, "[...], tudo que se acha na ideia se acha na palavra" (BRÉAL, 1992, 123).

Assim, "quanto mais a palavra se distancia de suas origens, mais está a serviço do pensamento: segundo as experiências que fazemos, ela se restringe ou estende, se especifica ou se generaliza" (BRÉAL, 1992, p.125).

Em Lyons (1982) também encontramos a discussão acerca do significado, e o autor explicita a necessidade de se resolver o que vem a ser o "significado". Segundo Lyons (1982, p. 133):

[...]ninguém conseguiu ainda apresentar uma resposta satisfatória. Uma das possíveis razões para isso é que, da forma como está elaborada, a pergunta é irrespondível. Apresenta duas pressuposições que são, no mínimo, problemáticas: a) de que aquilo a que nos referimos com a palavra 'significado' tem algum tipo de existência ou realidade; b) que tudo aquilo a que nos referimos usando este termo apresenta uma natureza semelhante, se não idêntica. Podemos chamar a uma de (a) pressuposição de existência e a outra de (b) pressuposição de homogeneidade.

De acordo com Lyons $(1982,134)$, portanto, a questão a ser respondida não é o que é significado, mas "qual o significado de 'significado'?" Segundo o referido autor, a mudança de foco imposta pela nova problematização faz com que o significado supere a relação de comprometimento com o pressuposto da homogeneidade, embora mantenha o significado comprometido com o pressuposto da existência. Essa mudança de foco também transfere a discussão das coisas para as palavras (LYONS, 1981).

Ainda adverte Lyons (1982, p. 135):

[...]. É fato importante que a maioria das palavras corriqueiras não apresentam um significado bem delineado, ou sequer um conjunto de significados bem determinados, cada um nitidamente distinto um do outro. A própria palavra 'significado' não escapa à regra. Não é de espantar, portanto, que haja tanta controvérsia entre os linguísticas e filósofos, com respeito às fronteiras da semântica [...].

Essa é uma discussão complexa e polêmica que persistirá, por isso não pretendemos esgotá-la em nossa abordagem. Ao longo de anos, décadas e séculos, esse debate continua vívido e instigando pesquisadores. Colocamos essa reflexão aqui apenas para relembrar aos leitores que exercer a pesquisa no campo da semântica é vivenciar continuamente os desafios das incertezas e é também transitar por um caminho cheio de surpresas, percalços, fracassos e possibilidades. É adentrar em um universo em continuum movimento (dialética), pois as palavras estão sempre em movimento. Segundo Bréal (1982, p. 80), "nas sociedades modernas, o sentido das palavras se modifica mais rápido que na antiguidade[...]”. É a palavra movimentando-se com o movimento do mundo, em uma relação de devir constante.

Em função dessa instabilidade e flexibilidade na conceituação do significado é que as diversas correntes teóricas da área da semântica divergem, ora atrelando o significado das palavras ao aspecto referencial, ora definindo-o como algo não referencial e associado ao aspecto intralinguístico, ora associando-o a questões de natureza cognitiva e, por fim, a questões de natureza enunciativa, como a corrente teórica na qual embasamos este trabalho.

Para Guimarães (2005, p. 07), "o que se diz é incontornavelmente construído na linguagem". Assim, o autor configura a Semântica do Acontecimento como uma semântica que "considera que a análise do sentido da linguagem deve localizar-se no estudo da enunciação, do acontecimento do dizer" (2005, p. 07). Portanto, não é objeto de interesse da Semântica do 


\section{$=$ TRAMA $=$}

Acontecimento a relação ontológica das palavras com as coisas, mas a relação simbólica, ou seja, a forma como as coisas são significadas.

Nesta perspectiva, o significado das palavras é tratado pela análise do sentido associado à designação dos nomes, designação essa dada em um enunciado determinado, resultado de uma enunciação específica.

\section{A SEMÂNTICA DO ACONTECIMENTO E A FORMAÇÃO DO SENTIDO}

A Semântica do Acontecimento é uma semântica com identidade própria. Ela coloca em seu espaço discursivo e analítico elementos como a política, a história, a ideologia e o acontecimento. Assim, ao tratar da enunciação, considera a constituição histórica do sentido, distanciando-se da lógica matemática e do estruturalismo biologicamente determinado (GUIMARÃES, 2005). Embora a teoria divirja, em muitos aspectos, de outros campos da própria semântica, ela assume uma postura de diálogo com outras perspectivas semânticas e outros campos. Especificamente, a Semântica do Acontecimento dialoga com a Pragmática, a Semântica Argumentativa e a Análise do Discurso. Nesta seção, tratamos de apresentar os pressupostos relevantes à compreensão desta proposta teórica.

Nesta perspectiva, a linguagem, ao se manifestar (acontecer), sempre fala de algo, de alguém ou de alguma coisa. A linguagem é o lócus onde os sentidos são construídos, e assim o é, porque, "[...] o que se diz é incontrolavelmente construído na linguagem" (GUIMARÃES, 2005, p. 07). Para a Semântica do Acontecimento, o sentido é um fenômeno que se manifesta na enunciação, ou seja, no acontecimento do dizer.

Segundo Guimarães (2005, p. 07):

[...] tomar o ponto de vista de uma semântica linguística é tomar o lugar de observação do sentido no enunciado. Deste modo, saber o que significa uma forma é dizer como seu funcionamento é parte da constituição do sentido no enunciado. [...] considerar o processo no qual uma forma funciona em um enunciado é considerar em que medida esta forma funciona num enunciado, enquanto enunciado de um texto. Ou seja, não há como considerar que uma forma funciona em um enunciado, sem considerar que ela funciona num texto, e em que medida ela é constitutiva do sentido do texto.

Na concepção da Semântica do Acontecimento, a relação de constituição de sentindo ocorre em uma relação de integração que extrapola a relação de sentido entre os signos, pois o sentido resulta da relação integrativa de unidades linguísticas, ou seja, é na relação integrativa que o sentido se constitui.

Um primeiro ponto a ser destacado é a noção de temporalidade. Não se trata aqui de uma referência ao tempo cronológico, mas uma temporalidade dada na enunciação. Para o autor, o acontecimento não se dá no tempo, nem no tempo do locutor; ao contrário, é o acontecimento quem temporaliza. Assim, "a temporalidade do acontecimento constitui o seu presente e um depois que abre o lugar dos sentidos, e um passado que não é lembrança de fatos anteriores" (GUIMARÃES, 2005, p. 12). Isto significa que na enunciação, que é o acontecimento do dizer, estabelece-se um presente, que remete a um memorável (passado) e a uma latência de futuro. Mas, além do fato de o acontecimento ser o responsável pela temporalidade, é importante também compreender como se dá a enunciação, que se organiza, nesta proposta, pelas noções de espaço da enunciação e cena enunciativa.

Segundo Guimarães (2005), o espaço da enunciação, que é um espaço político, coloca em jogo a relação entre falante e língua, considerando o falante uma categoria linguística e enunciativa. Há de se considerar que, para o autor, "o falante não é uma figura empírica, mas uma figura política constituída pelos espaços da enunciação" (GUIMARÃERS, 2005, p. 18). 


\section{$=$ TRAMA $=$}

Nesse espaço da enunciação, constituído pelos seus agentes - língua e falante -, estabelece-se a cena enunciativa, em que aquele que fala e aquele para quem se fala não são simplesmente pessoas, mas configurações do agenciamento enunciativo, lugares constituídos pelos dizeres. O Locutor é definido como o lugar que se representa no próprio dizer como fonte deste dizer, no entanto, esse Locutor só pode falar enquanto predicado por um lugar social, denominado pelo autor de alocutor: "se o falante é agenciado em o lugar que diz, este lugar que diz só o faz na medida em que o falante se divide em lugar que diz e lugar social de dizer (chamamos este lugar de alocutor)" (GUIMARÃES, 2018, p, 44). Além disso, há um lugar de dizer, definido como enunciador, que pode ser individual, genérico e universal. Como exemplo, trazemos aqui a situação em que os pais nomeiam um filho. O pai só o faz de um lugar social que é o da paternidade. Então, tomando uma enunciação em que podemos parafrasear como "como pai, dou ao meu filho o nome X", constrói-se uma cena em que o falante é agenciado no espaço enunciativo da língua portuguesa, com certas obrigações de dizer (dar nomes aos filhos, por exemplo) enquanto alocutor-paterno. Ao mesmo tempo, há um lugar de dizer individual do qual se enuncia a relação do nome com a pessoa nomeada. Na dinâmica da cena, o alocutorpaterno apresenta o enunciador-individual e estabelece a conexão específica entre o nome e o filho (GUIMARÃES, 2018, p, 191).

Um terceiro e último conceito a ser aqui apresentado é o da designação. Para Guimarães (2005), designação se diferencia de nomeação e referenciação (denotação). A nomeação é apenas o funcionamento semântico pelo qual algo recebe um nome, e a referenciação é a particularização desse algo. Assim, nomeamos determinado objeto físico como cadeira e, ao apontarmos para uma cadeira específica em uma dada enunciação, temos a sua referência ou denotação. Já a designação é a significação de um nome, em que se considera a relação deste com outros nomes presentes em um enunciado dado em uma enunciação específica. A análise apresentada neste artigo busca mostrar a designação dos nomes história e tempo, enquanto sentidos atribuídos nos enunciados recortados como corpus de análise.

\section{O FENÔMENO DO ACONTECIMENTO (ENUNCIAÇÃO) E SUAS INTERFACES}

Como afirmado na Introdução, a Semântica do Acontecimento possui interface com outras discussões teóricas. Além disso, ela não é a primeira e também não é a única teoria a se debruçar sobre conceitos como enunciação, enunciado, tempo e política. Aqui, apresentamos, brevemente, alguns autores nos quais identificamos aproximações e distanciamentos conceituais em relação à proposta de Guimarães.

Na perspectiva de Benveniste (1976, p. 136), "o sentido de uma unidade linguística define-se como a sua capacidade de integrar uma unidade de nível superior". Ainda, segundo o autor (1976, p. 131), "[...] uma unidade linguística só será recebida como tal se se puder identificar em uma unidade mais alta". Identificar a relação de sentido não é uma tarefa fácil e simples, dada a discrição das unidades linguísticas. Segundo o referido autor, por causa da discrição das unidades linguísticas, os elementos linguísticos permitem duas formas de relação: 1) a relação entre elementos que estão no mesmo nível; 2) a relação entre elementos que estão em níveis diferentes. É necessário, portanto, dar atenção à distinção entre os níveis ${ }^{2}$, pois o que define a relação é a posição de um elemento em referência à posição de outro elemento. Ou seja, a relação entre elementos que estão no mesmo nível é uma relação distribucional, e a relação entre os elementos que estão em níveis diferentes é uma relação integrativa. Para o autor supracitado, deve-se dedicar a atenção à relação integrativa, pois a relação distribucional

2 Para Benveniste, o nível é um operador (BENVENISTE, 1976, p. 131). 


\section{$=\mathrm{T} R A M A=$}

não consegue colocar em evidência a relação entre os elementos de níveis diferentes (BENVENISTE, 1976).

De acordo com Benveniste (1976), uma unidade linguística só será distintiva em determinado nível se ela se identificar como parte integrante da unidade linguística superior, nesse caso, ela se tornará o elemento integrante. Assim, "um signo é materialmente função dos seus elementos constitutivos, mas o único meio de definir esses elementos como constitutivos consiste em identificá-los no interior de uma unidade determinada onde preenchem uma função integrativa" (BENVENISTE, 1976, p. 133).

Porém, essa relação de integração tem um limite, sendo que "o limite superior é traçado pela frase ${ }^{3}$, que comporta constituintes, mas que [...] não pode integrar nenhuma unidade mais alta" (BENVENISTE, 1976, p. 134). A frase é o limite da relação de integração porque: a) contém signos e é em si mesmo um signo; b) as frases são incontáveis; c) as frases não têm distribuição e nem emprego no nível superior; d) não é possível inventariar; e) pertence ao universo da comunicação (discurso) (BENVENISTE, 2005).

A relação de sentido, na concepção de Benveniste, pode ser ilustrada com o esquema abaixo.

Signos $\longrightarrow$ Palavras $\longrightarrow$ Frases $\longrightarrow$ Relação de Sentidos

Para a Semântica do Acontecimento, assim como para Benveniste (1976), a constituição da relação de sentido dá-se a partir da relação integrativa, porém a Semântica do Acontecimento rechaça a ideia de limitação da relação de integração e segmentação da linguagem. Soa estranho à Semântica do Acontecimento a ideia de que a linguagem precise ser segmentada para ser analisada, uma vez que a segmentação tende a romper os fortes e intensos laços integrativos entre os elementos linguísticos.

A Semântica do Acontecimento também se distancia da ideia de limite para a relação de integração, defendida por Benveniste (1976), pois ignorar a relação de integração do enunciado com o texto e com a enunciação é negligenciar a relação da linguagem com o mundo, uma vez que, segundo Guimarães (2005, p. 07), "[...] há uma passagem do enunciado para o texto ${ }^{4}$, para o acontecimento [...]".

\begin{tabular}{|c|c|c|}
\hline Componente Linguístico (CL) & Situação (S) & Componente Retórico (CR) \\
\hline $\begin{array}{l}\text { Atribui significação } \\
\text { (Enunciado) }\end{array}$ & Descrição da situação & $\begin{array}{l}\text { Atribui Sentido } \\
\text { (Enunciação) }\end{array}$ \\
\hline
\end{tabular}

Para Ducrot (1987, p. 57), o sentido é constituído a partir da relação entre o "componente linguístico (CL), o componente retórico (CR) e a situação (S). O componente linguístico atribui ao enunciado uma significação, e o componente retórico, a partir da significação do enunciado e a descrição da situação, define o sentido da enunciação". Veja-se o esquema ilustrativo abaixo:

\footnotetext{
3 "A frase realiza-se em palavras, mas as palavras não são simplesmente os seus segmentos. Uma frase constitui um todo, que não se reduz à soma de suas partes; o sentido inerente a esse todo é repartido entre o conjunto dos constituintes. A palavra é um constituinte da frase, efetua-lhe a significação; mas não aparece necessariamente na frase com o sentido que tem como unidade autônoma." (BENVENISTE, 1976, P. 132)

${ }^{4}$ Texto é entendido aqui como a unidade de significação integrada pelo enunciado (GUIMARÃES, 2007).
} 


\section{$=$ TRAMA $=$}

Para o autor (1987), o enunciado ocorre na relação com o contexto. Assim, “[...] tentar representar o efeito casual do enunciado, caso este fosse produzido fora do contexto, é enganar-se a si mesmo: uma ocorrência fora do contexto não passa de uma ocorrência produzida em um contexto artificialmente simplificado [...]" (DUCROT, 1987, p. 14). Nesses termos, a Semântica Argumentativa rejeita a ideia de que a língua se restringe a um "conjunto de regras independentes de toda enunciação e contexto" (NASCIMENTO, 2005, p. 17).

Pode-se, assim, afirmar, conforme o exposto acima, que Guimarães (2005), Benveniste $(1976,2005)$ e Ducrot $(1987)$ concordam quanto ao fato de que a produção de sentido se dá a partir de um processo de relação. Todavia, é evidente que os referidos autores discordam quanto à forma como essa relação ocorre.

Não é objetivo deste trabalho analisar as divergências entre esses autores no que tange à produção de sentido. Assim, volta-se aqui a atenção ao objetivo deste estudo: estudar a designação, especificamente, o que é peculiar ao sentido dos nomes.

A linguagem é um espaço de potencialidades, um lugar em que fenômenos linguísticos distintos coexistem; uma estrutura plástica em expansão, um devir continum. Em razão da plasticidade da linguagem, "o emprego das formas, parte necessária de toda descrição, tem dado lugar a um grande número de modelos, tão variados quanto os tipos linguísticos dos quais eles procedem" (BENVENISTE, 2006, p. 81-82). Isso acontece porque "a diversidade das estruturas linguísticas, $[\ldots]$, não se deixa reduzir a um pequeno número de modelos, [...]" (BENVENISTE, 2006, p. 82).

É nesse espaço plástico da linguagem que o Acontecimento (enunciação), enquanto fenômeno da língua, se manifesta. Para Benveniste (2006, p.82), A "enunciação é [...] colocar em funcionamento a língua [...]". Segundo Ducrot (1987, p. 164), o enunciado "é a manifestação particular, como a ocorrência hic et nunc de uma frase". E "a realização de um enunciado é de fato um acontecimento histórico: é dado existência a alguma coisa que não existia antes de se falar e que não existirá mais depois. É esta aparição momentânea que chamo de enunciação" (DUCROT, 1987, p.168). Para Guimarães (2005, p.11), a "enunciação, enquanto acontecimento de linguagem, se faz pelo funcionamento da língua". Na perspectiva de Rancière (2017, p. 283), o acontecimento "é a conjunção de um conjunto de fatos e uma subjetivação." Porém, adverte Rancière (2017, p.283), "não há acontecimento sem sentido de acontecimento, sem subjetivação de acontecimento". Ainda, segundo o referido autor (2017, p. 283), "[...] não há acontecimento sem "ideologia", sem um alguém por quem e para quem ele tem sentido de acontecimento".

Compreende-se que o acontecimento é a exteriorização do pensado, ou seja, a manifestação concreta do pensado no mundo. Ressalta-se que, ao fazer referência à manifestação concreta, não se está fazendo referência ao ser físico e nem ao mundo estritamente físico. Assim o é, porque, ao enunciar-se, faz-se-o na condição de seres simbólicos, que vivem em um mundo permeado por símbolos. É relevante destacar que o acontecimento não se reduz apenas à exteriorização do pensado.

Para a Semântica do Acontecimento, o acontecimento enquanto fenômeno de linguagem é um evento complexo que envolve temporalidade, política, espaço de enunciação e relação locutor-língua, sendo a temporalidade é uma marca essencial da enunciação. É importante destacar que, para a Semântica do Acontecimento, o fenômeno do acontecimento (enunciação) não se inscreve como um fato no tempo. "Ou seja, não é um fato novo enquanto distinto de qualquer outro ocorrido antes no tempo. [...] O acontecimento instala sua própria temporalidade" (GUIMARÃES, 2005, p. 11-12), e essa temporalidade do acontecimento independe do sujeito. 


\section{$=$ TRAMA $=$}

Na relação entre acontecimento e tempo, o sujeito é capturado pela temporalidade do acontecimento (GUIMARÃES, 2005). Esse entendimento também é apresentado por Benveniste (1989, p. 85), quando afirma que a temporalidade do acontecimento "[...] é produzida, na verdade, na e pela enunciação (acontecimento). Da enunciação procede a instauração da categoria do presente, e da categoria do presente nasce a categoria do tempo". Pode-se, assim, afirmar que o tempo do acontecimento não se inscreve na temporalidade convencional, pois não é um tempo construído a partir do sujeito. A temporalidade do acontecimento é própria do acontecimento. Ou seja, a origem da temporalidade do acontecimento reside no próprio acontecimento da linguagem. "Todo acontecimento de linguagem significa porque projeta em sim mesmo um futuro” (GUIMARÃES, 2005, p. 12)

Segundo Guimarães (2005, p. 14),

[...] o acontecimento de linguagem não se dá no tempo, nem no tempo do locutor, mas é um acontecimento que temporaliza; uma temporalidade em que o passado não é um antes mas um memorável recortado pelo próprio acontecimento que tem também o futuro como uma latência de futuro. O sujeito não fala no presente, no tempo, embora o locutor o represente assim, pois só é sujeito enquanto afetado pelo interdiscurso, memória de sentidos, estruturada pelo esquecimento, que faz a língua funcionar.

O acontecimento, enquanto espaço de temporalização, é um fenômeno singular, pois encera em si a integralidade do tempo (passado, presente e futuro). Ao se manifestar, o acontecimento instaura o seu presente, recupera o passado (memorável), ou seja, relações de acontecimentos anteriores, e projeta o futuro, possibilidade de outros acontecimentos.

Outro elemento importante, aos olhos da Semântica do Acontecimento, para compreender-se a manifestação do acontecimento, é a política. Vale ressaltar que o campo da política é complexo, pois é um campo constituído por diferentes perspectivas.

Para Rancière (2018), a filosofia e a política se encontram no desentendimento, que se situa na fala (um tipo determinado de fala), ou seja, "aquela em que um dos interlocutores ao mesmo tempo entende e não entende o que o outro diz" (RACNCIĖRE, 2018, p. 10). O desentendimento, ainda de acordo com Rancière (2018), não é uma relação de opiniões divergentes, é, sim, uma relação em que um interlocutor entende e não entende o que foi expresso. "É o conflito entre aquele que diz branco e aquele que diz branco, mas não entende a mesma coisa, ou não entende que o outro diz a mesma coisa com o nome brancura" (RANCIĖRE, 2018, p. 10). Por isso, de acordo com o raciocínio do referido autor, o desentendimento não deve ser compreendido como ignorância ou um mal-entendido resultante da imprecisão das palavras.

Assim, a política não é redutível ao conflito entre partes distintas. Conforme Rancière (2018, p. 26), "a política existe quando a ordem natural da dominação é interrompida pela instituição de uma parte dos sem-partes".

A política existe porque aqueles que não têm direito de ser contados como seres falantes conseguem ser contados, e instituem uma comunidade pelo fato de colocarem em comum o dano que nada mais é que o próprio enfrentamento, a contradição de dois mundos alojados num só: o mundo em que estão e aquele em que não estão, o mundo onde há algo "entre" eles e aqueles que não os conhecem como seres falantes e contáveis e o mundo onde não há nada (RANCIĖRE, 2018, p. 40-41).

A política não ocorre em função de uma relação de poder ou de uma relação de resistência, tampouco é espaço de afirmação. Se tudo é político, assevera Rancière (2018), nada é político. Efetivamente "a política não é feita de relações de poder, é feita de relações 


\section{$=$ TRAMA $=$}

entre mundos" (RANCIÈRE, 2018, p. 56). Nessa linha de raciocínio, a política não é um fenômeno recorrente nas sociedades, mas um fenômeno raro.

Em contraposição às ideias de Rancière acerca de política, Guimarães (2005) defende a concepção de que a política é uma relação de conflitos entre o normativo e a desigualdade do real em um processo em que os desiguais impõem seu pertencimento. É a afirmação da igualdade, do pertencimento do sem parte no todo em contraposição à divisão desigual do real, impondo-Ihe uma redivisão, um refazer cujo objetivo é estabelecer o pertencimento de todos no todo. Para Guimarães (2005, p. 16), "[...] o político é incontornável porque o homem fala. O homem está sempre a assumir a palavra, por mais que esta Ihe seja negada". Esta afirmação de política apresenta uma contradição aparente, pois a desigualdade é apresentada como algo necessário às relações sociais, enquanto a reivindicação de pertencimento da igualdade assume o caráter de abuso e de impróprio. Na percepção de Guimarães (2005, p. 16), "esta desmontagem é o esforço do poder em silenciar a contradição, na busca de um político como ação homogeneizadora [...]".

Pode-se sintetizar o pensamento de Guimarães (2005) quanto à política da seguinte forma: a política é uma relação de conflito que se estabelece a partir da afirmação da igualdade e do pertencimento de um povo, grupo ou indivíduo em relação à divisão desigual do real.

Essa mesma ideia geral de política é aplicada à particularidade da linguagem. Nessa concepção, a linguagem é um fenômeno político, e assim o é, porque ocorre em espaços de enunciação. A natureza política da linguagem está diretamente relacionada ao fato de ser a linguagem um espaço regulado e um espaço de disputa pela palavra (GUIMARÃES, 2005). A discussão sobre política da linguagem coloca-nos dentro da discussão, ainda que sinteticamente, sobre a relação entre língua e falante (espaço de enunciação).

A relação entre a língua e falante requer uma (várias) língua(as) e um falante(s). De acordo com Guimarães, (2005, p. 18), "só há língua porque há falantes e só há falantes porque há línguas". No entanto, para Guimarães (2005), a relação língua e falante pode produzir um falseamento dessa relação, se se confundir essa relação (língua e falante) com a relação empírica que reduz o falante à condição de falar uma língua específica (exemplo: na Itália, falase o italiano; na França, fala-se o francês etc.). "Os falantes são essas pessoas enquanto determinadas pelas línguas que falam" (GUIMARÃES, 2005, p. 18). Nesse sentido, os falantes são sujeitos (categoria linguística e enunciativa) da língua na medida em que são formados pelo espaço de enunciação.

Falar é tomar para si a palavra em um espaço dividido de línguas e falantes. Apropriarse da palavra é colocar-se no lugar que enuncia, assumir o lugar de Locutor (L). No entanto, o Locutor não é o sujeito empírico, mas o "lugar que se representa no próprio dizer como fonte deste dizer" (GUIMARÃES, 2005, p. 23). O Locutor só pode ser a fonte do enunciado se ele tiver sua identidade anulada e assumir a identidade outorgada pelo lugar social de locutor (locutor díspar de si). Este lugar social do locutor é denominado por Guimarães (2005) de alocutor-x". Conclui o referido autor (2005, p. 24) que "sem esta disparidade não há enunciação".

De acordo com Guimarães (2018, p. 25), o falante não é uma figura empírica, "[...] é uma figura linguística constituído por uma relação de línguas." "O falante é uma figura política, constituída pelos espaços de enunciação" (GUIMARÃES, 2005, p. 18). Os espaços de enunciação são espaços de funcionamento de línguas, são territorialidades de disputas (GUIMARÃES, 2005).

Segundo Guimarães (2005, p. 18-19), 


\section{$=$ TRAMA $=$}

Os espaços de uma enunciação são espaços de funcionamento de línguas, que se dividem, redividem, se misturam, desfazem, transformam por uma disputa incessante. São espaços "habitados" por falantes, ou seja, por sujeitos divididos por seus direitos ao dizer e aos modos de dizer. São espaços constituídos pela equivocidade própria do acontecimento: da deontologia que organiza e distribui papéis, e do conflito, indissociado desta deontologia, que redivide o sensível, os papéis sociais. O espaço de enunciação é um espaço político [...].

A concepção política da linguagem remete para a dimensão da elevação da palavra. Segundo Guimarães (2005), a palavra manifesta-se em cenas enunciativas que se caracterizam por formar modos específicos de encontro com a palavra, considerando as figuras da enunciação e as formas linguísticas (GUIMARÃES, 2005, p. 23).

A cena enunciativa é aqui compreendida como:

[...] especificações locais nos espaços de enunciação.

[...] um espaço particularizado por uma deontologia específica de distribuição dos lugares de enunciação no acontecimento. Os lugares enunciativos são configurações do agenciamento enunciativo para "aquele que fala" ou "aquele para quem se fala". Na cena enunciativa "aquele que fala" ou "aquele para quem se fala" não são pessoas mas uma configuração do agenciamento enunciativo. São lugares constituídos pelos dizeres e não pessoas dona de seu dizer. [...] é necessário considerar o próprio modo de constituição destes lugares pelo funcionamento da língua (GUIMARÃES, 2005, p. 23).

Para que a distribuição dos lugares ocorra, é necessário que a temporalização específica do acontecimento se efetive, pois a temporalização específica do acontecimento é o fundamentum da cena enunciativa.

\section{METODOLOGIA}

Esta pesquisa foi realizada em cinco etapas. Na primeira etapa, definimos o locus da pesquisa. Escolhemos trabalhar com LD utilizado por uma unidade escolar da cidade de João Pessoa-PB, e a escolha da escola levou em consideração a questão logística, ou seja, a facilidade de acesso do(s) pesquisador(es) à unidade escolar. Já a escolha por uma unidade escolar do município de João Pessoa se deu em razão da importância política, cultural e econômica de João Pessoa para o Estado da Paraíba (capital do Estado, maior densidade demográfica do Estado, maior PIB do Estado etc.).

$\mathrm{Na}$ segunda etapa, levantaram-se as informações acerca do número de escolas de ensino fundamental existentes no município de João Pessoa. Identificamos, com base nos dados da Secretaria Municipal de Educação, que a rede municipal de ensino de João Pessoa possui 99 (noventa e nove) unidades escolares de ensino fundamental.

Na terceira etapa da pesquisa, selecionamos a unidade escolar que forneceria o LD de história o qual tornar-se-ia objeto de análise desta pesquisa. Para a seleção da escola, levamos em consideração os seguintes aspectos: 1) facilidade de acesso do(s) pesquisador(es) à unidade escolar; 2) densidade populacional do bairro e o número de unidade(s) escolar(es) disponíveis no bairro; e 3) oferta do ensino fundamental (anos finais) pela unidade.

A partir dos critérios estabelecidos, escolhemos trabalhar com o LD de História ( $6^{\circ}$ ano) utilizado pela Escola Municipal de Ensino Fundamental Chico Xavier, situada no bairro Jardim Oceania. A escola Chico Xavier está situada em uma localidade de fácil acesso, o que viabiliza a logística dos pesquisadores; o bairro Jardim Oceania é o terceiro bairro com maior discrepância entre distribuição de unidade escolar de ensino fundamental por pulação, 01escola de ensino fundamental para 15.283 habitantes, e por fim, a escola Chico Xavier oferta o ensino fundamental anos iniciais e finais. 
$\mathrm{Na}$ quarta etapa da pesquisa, realizamos a visita à Escola Municipal Chico Xavier. Na ocasião, houve uma conversa com a coordenação da unidade, quando foi explicado o objetivo da pesquisa. Após a aprovação da escola, iniciamos o processo de escolha do LD de história.

Vale destacar que a escolha do livro didático foi feita a partir da indicação da escola. Para esta pesquisa, interessava um LD de história que estive em uso pela escola e cuja adoção fosse uma escolha da equipe de professores da unidade. Assim, a partir das informações da escola, o LD de história selecionado foi História, Sociedade \& Cidadania ( $6^{\circ}$ ano), de autoria de Alfredo Boulos Júnior, Editora FTD, ano 2015. Escolhemos o livro de História do $6^{\circ}$ ano por ser esta série uma séria de transição entre o ensino fundamental dos anos iniciais e o ensino fundamental dos anos finais.

Definido o LD de história, passamos à quinta etapa do processo, ou seja, à análise do LD propriamente dita. A primeira fase dessa etapa implicou a leitura do material e a compreensão da forma como o conteúdo está estruturado no livro. O LD de história em análise estrutura-se em quatro Unidades Temáticas e em quatorze Capítulos, conforme demonstra o quadro abaixo.

Quadro 1- Estrutura do Livro Didático de História.

\begin{tabular}{|c|c|c|c|c|}
\hline Unidade & $\begin{array}{l}\text { Título da } \\
\text { Unidade }\end{array}$ & $\begin{array}{c}\mathrm{N}^{\circ} \mathrm{de} \\
\text { capítulos } \\
\text { por } \\
\text { unidade }\end{array}$ & Títulos dos Capítulos & $\begin{array}{l}\text { Organização dos } \\
\text { Capítulos }\end{array}$ \\
\hline \multirow{2}{*}{1} & \multirow{2}{*}{$\begin{array}{c}\text { História } \\
\text { Cultura e } \\
\text { Patrimônio }\end{array}$} & \multirow{2}{*}{2} & Capítulo 1: História e fontes históricas & 5 seções temáticas \\
\hline & & & Capítulo 2: Cultura, patrimônio e tempo & 6 seções temáticas \\
\hline \multirow{3}{*}{2} & \multirow{3}{*}{$\begin{array}{l}\text { O Legado dos } \\
\text { Nossos } \\
\text { Antepassados }\end{array}$} & \multirow{3}{*}{3} & $\begin{array}{l}\text { Capítulo 3: OS primeiros povoadores da } \\
\text { Terra }\end{array}$ & 7 seções temáticas \\
\hline & & & Capítulo 4: A "Pré-História" brasileira & 4 seções temáticas \\
\hline & & & $\begin{array}{l}\text { Capítulo 5: Os Indígenas: diferenças e } \\
\text { semelhanças }\end{array}$ & 3 seções temáticas \\
\hline \multirow{4}{*}{3} & \multirow{4}{*}{$\begin{array}{c}\text { Vida Urbana: } \\
\text { Oriente e } \\
\text { África }\end{array}$} & \multirow{4}{*}{4} & Capítulo 6: Mesopotâmia & 8 seções temáticas \\
\hline & & & Capítulo 7: O Egito antigo e o Reino de Kush & 6 seções temáticas \\
\hline & & & Capítulo 8: Hebreus, fenícios e persas & 5 seções temáticas \\
\hline & & & Capítulo 9: China & 2 seções temáticas \\
\hline \multirow{7}{*}{4} & \multirow{5}{*}{$\begin{array}{l}\text { A Luta por } \\
\text { Direitos }\end{array}$} & \multirow{5}{*}{5} & $\begin{array}{l}\text { Capítulo 10: O mundo grego e a } \\
\text { democracia }\end{array}$ & 9 seções temáticas \\
\hline & & & Capítulo 11: A cultura grega & 6 seções temáticas \\
\hline & & & Capítulo 12: Roma Antiga & 4 seções temáticas \\
\hline & & & Capítulo 13: O Império Romano & 3 seções temáticas \\
\hline & & & $\begin{array}{l}\text { Capítulo 14: A crise de Roma e o Império } \\
\text { Bizantino }\end{array}$ & 4 seções temáticas \\
\hline & Bibliografia & & & \\
\hline & $\begin{array}{l}\text { Mapas de } \\
\text { apoio }\end{array}$ & & & \\
\hline
\end{tabular}

Fonte: O próprio autor.

Na segunda fase da quinta etapa, realizamos o processo de seleção das palavras a serem analisadas. A escolha lexical levou em consideração a relevância das palavras para a compreensão dos conceitos básicos propostos nos capítulos do livro, ou seja, a relevância no processo de apropriação dos conceitos fundamentais ao ensino de História do $6^{\circ}$ ano. 
Considerando este critério, selecionamos quarenta palavras com recorrência total de 729 (setecentos e vinte e nove) vezes, conforme demostra o gráfico abaixo.

\section{Gráfico 4 - Recorrência das Palavras}

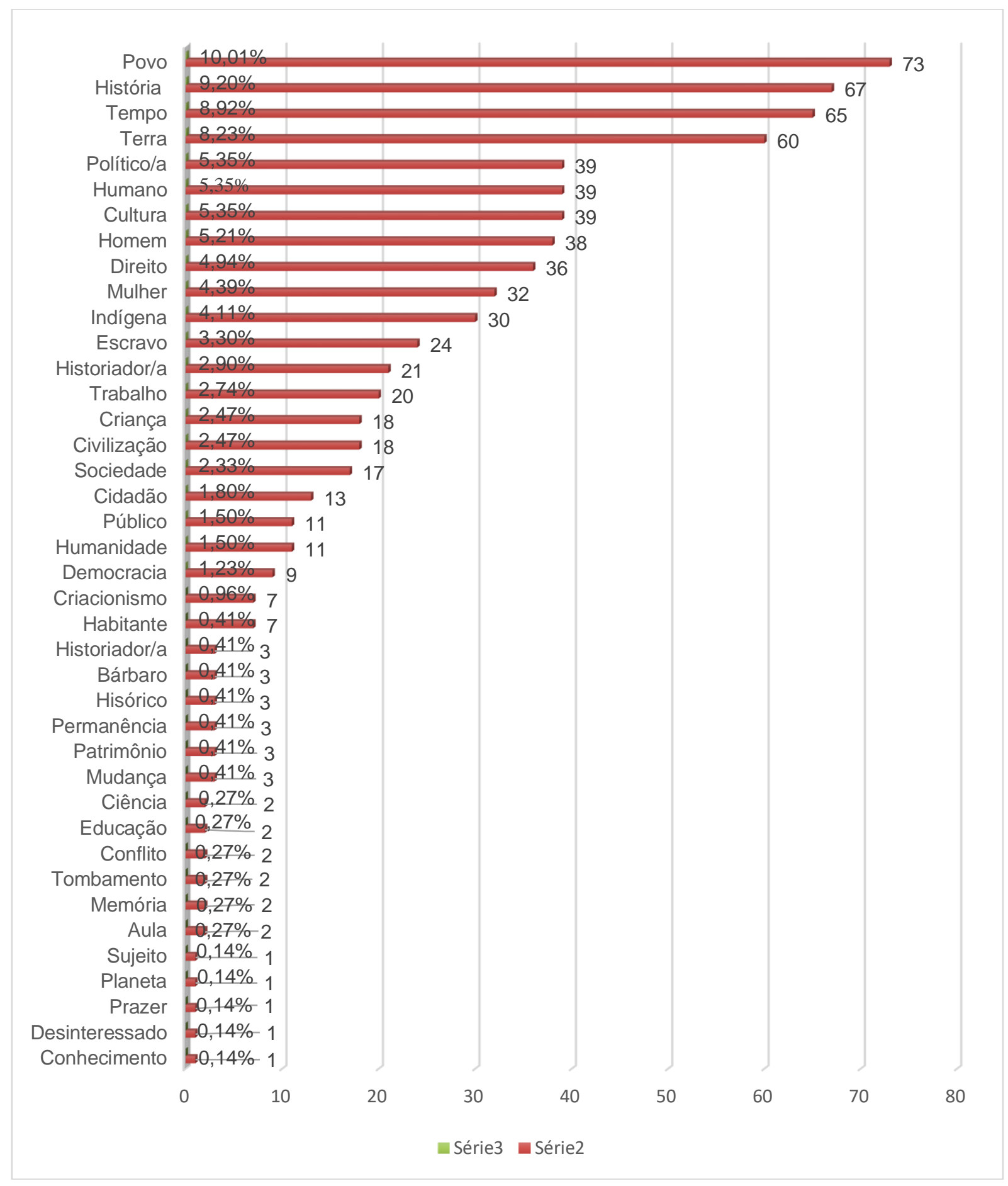

Fonte: O próprio autor.

Após a identificação das quarenta palavras e a recorrência destas, fizemos o processo de seleção de duas palavras a serem analisadas. Com base no critério de relevância das palavras no processo de apropriação dos conceitos fundamentais ao ensino de História do $6^{\circ}$ ano, as palavras selecionadas foram "história" e "tempo". É importante destacar que é no $6^{\circ}$ 


\section{$=$ TRAMA $=$}

ano que os alunos estão sendo introduzidos no mundo da História enquanto ciência, e os conceitos de história e tempo são essenciais à compreensão do que é história e do que é tempo, bem como essenciais à apropriação dos demais conceitos da área.

Para realizar a análise das palavras "história" e "tempo", escolhemos enunciados extraídos do texto do referido LD de História. A escolha dos enunciados deu-se após leitura cuidadosa do referido texto em sua integralidade. Assim, escolhemos os enunciados que sintetizavam a discussão acerca daqueles temas (história e tempo).

A análise das palavras "história" e "tempo", neste trabalho, realiza-se a partir da configuração do Domínio Semântico de Determinação (DSD). O DSD é adequado para este tipo de análise, pois considera as relações de sentido estabelecidas entre as palavras de um ou mais textos com a palavra em análise (GUIMARÃES, 2018). Para análise empregamos, também, obras de Marx (2011) e Koselleck (2014) etc.

Nessa análise, usaremos os sinais do sinal determina, atribui sentido à palavra temos $\quad O \longrightarrow$ seguinte: $Y \quad X$, onde $Y$ determina (atribui sentido) $X$; ou $Y$ $X$, neste caso, $X \quad$ determina (atribui sentido) $Y$. Há ainda o sinal que significa relação de sinonímia $\frac{X}{Y}$, assim representado $X$ é sinonímia de $Y$; e o sinal que significa relação de antonímia $X-Y$, assim representado $X$ é antonímia de $Y$. Para a realização da análise das palavras "histórias" e "tempo" extraímos quatro enunciados do capítulo 01 da unidade 01 do LD de história.

Enunciado 1: "Reparou o desinteresse desses alunos pela aula? Será que é aula de História? Se for, por que será que estão tão desinteressados? Um dos motivos, talvez, seja ver a História como uma matéria "decoreba", um amontoado de datas e nomes de gente antiga que nada tem a ver com a nossa vida hoje". (BOULOS JUNIOR, 2015, p. 10).

Enunciado 2: "Já o grupo de alunos abaixo está estudando História com gosto; talvez porque vejam a História como uma fonte de prazer e conhecimento. E você, que ideia faz da História? O que a História estuda? Você acha que a História pode ajudar as pessoas no dia a dia?" (BOULOS JUNIOR, 2015, p. 10).

Enunciado 3: "Vimos que cada povo possui uma cultura. Assim, com base em sua cultura, os povos criaram diferentes calendários, ou seja, diferentes modos de contar e dividir o tempo. Para dar início à contagem do tempo, cada povo escolheu uma data que é importante para ele. [...]." (BOULOS JUNIOR, 2015, p. 35).

Enunciado 4: "Ao longo do tempo, os seres humanos dominaram técnicas para produzir o fogo, inventaram as ferramentas, a agricultura, a escrita, o comércio, a cidade, a pintura, a música e, com isso, foram fazendo a História. Esse tempo resultante da ação dos seres humanos sobre a terra é chamado de tempo histórico. É, portanto, um tempo relacionado às experiências coletivas dos seres humanos, à história da humanidade". (BOULOS, 2015, p. 37).

\section{AS DESIGNAÇÕES "HISTÓRIA" E "TEMPO" NO LIVRO DIDÁTICO "HISTÓRIA, SOCIEDADE \& CIDADANIA" DO $6^{\circ}$ ANO DO ENSINO FUNDAMENTAL}

A incursão no LD de história do $6^{\circ}$ ano do Ensino Fundamental (anos finais), com o objetivo de analisar as designações "história" e "tempo" sob a égide da Semântica do Acontecimento, coloca o pesquisador diante de uma cena enunciativa em que a enunciação agência o falante e o divide em Locutor (L) e o Locutário (LT). "O Locutor apresenta assim aquele que diz como um eu que fala a um tu. O funcionamento da língua no espaço de enunciação se apresenta como uma alocução de L para LT, como uma cena enunciativa" 


\section{$=$ TRAMA $=$}

(GUIMARÃES, 2018, p. 55). Nesse caso, é relevante destacar que "[...] o falante ao ser agenciado se divide em L e alocutor" (GUIMARÃES, 2018, p. 56).

Segundo Guimarães (2018, p. 56),

[...] alocutor é um lugar que deve ser especificado, faz parte deste lugar ser especificado pela cena enunciativa. O alocutor é sempre um alocutor-x, ou seja, um alocutor que é a cada acontecimento específico por uma caracterização do próprio acontecimento enunciativo e este alocutor constitui por seu dizer um lugar seu correlato numa alocução específica [...].

A cena enunciativa opera outra divisão, a divisão alocutor-x e enunciado. Ao enunciar, o alocutor-x fala de um lugar social (pai, autor, filho etc.), mas também fala de um lugar de dizer (individual, coletivo, genérico e universal). O lugar do dizer é o enunciador.

Nos enunciados [01] e [02], o alocutor-x é o autor; o alocutário-x são os alunos-leitores, e o enunciador é individual. É importante ressaltar que a definição desse enunciador como um enunciador individual pode causar estranheza, uma vez que a cena enunciativa analisada parece deixar indícios que possibilitam identificar o enunciador como um enunciador universal ou como um enunciador coletivo. Embora seja plausível essa possibilidade, é necessário considerar que a cena enunciativa em questão, se bem observada, não fundamenta tal conclusão. O que se observa na cena enunciativa em questão é um enunciador individual cujo lugar social de autor remete ao lugar social de cientista (enunciador universal) e de pertencente a uma comunidade específica de cientistas (enunciador coletivo). Porém, na cena enunciativa em análise, não é a ciência nem a coletividade que se manifestam, embora saibamos que este Locutor pertença a esses dois lugares sociais.

A análise da palavra história será feita a partir dos enunciados 01 e 02 expostos abaixo.

Enunciado 01: "Reparou o desinteresse desses alunos pela aula? Será que é aula de História? Se for, por que será que estão tão desinteressados? Um dos motivos, talvez, seja ver a História como uma matéria "decoreba", um amontoado de datas e nomes de gente antiga que nada tem a ver com a nossa vida hoje. (BOULOS JUNIOR, 2015, p. 10).

Enunciado 02: "Já o grupo de alunos abaixo está estudando História com gosto; talvez porque vejam a História como uma fonte de prazer e conhecimento. E você, que ideia faz da História? O que a História estuda? Você acha que a História pode ajudar as pessoas no dia a dia?" (BOULOS JUNIOR, 2015, p. 10).

No enunciado [01], a relação de Domínio Semântico de Determinação (DSD) estabelece-se conforme demostra o esquema abaixo.

Amontoado de nomes de gente antiga

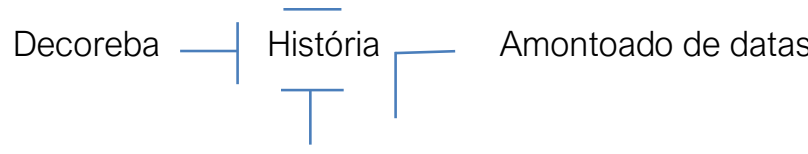

Desinteresse

História

No enunciado [01], "história" a) é determinada por desinteresse, decoreba, amontoado de nomes de gente antiga e amontoado de datas; b) estabelece uma relação de antonímia com "vida"; c) é designada como um componente curricular formal (disciplina), estruturada 


\section{$=$ TRAMA $=$}

pedagogicamente sob uma base metodológica que privilegia o processo de memorização de datas e nomes desvinculados da vida cotidiana dos alunos; e d) remete ao sentido de ultrapassado. "História" na enunciação [01], portanto, remete ao memorável que se refere à disciplina História como um espaço constituído de uma série de fatos históricos do passado sem relação com os fenômenos sociais do presente. Nesses termos, a designação "história" tem sentido negativo.

No enunciado [02], a relação de Domínio Semântico de Determinação estabelece-se conforme demostra o esquema abaixo.

DSD 2

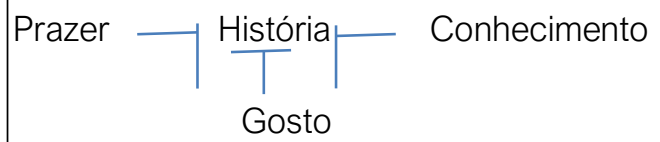

História — Prazer/Conhecimento

No enunciado [02], "história" a) é determinada por gozo, prazer e conhecimento; b) estabelece uma relação de sinonímia com prazer e conhecimento; c) é designada como componente curricular formal (disciplina) prazeroso e produtor de conhecimento; e d) tem o sentido de dinamicidade, prazer e conhecimento. Nesses termos, "história" tem sentido positivo.

No enunciado [02], a designação "história" estabelece a divisão entre a enunciação e o real. No plano da realidade, a disciplina História é um componente curricular escolar que está associado a temas ultrapassados e sem validade prática para as pessoas. Assim, a disciplina História enfrenta a rejeição da maioria dos alunos das escolas no Brasil. A partir da enunciação [02], a disciplina História se apresenta como um componente curricular atualizado, dinâmico, prazeroso e gerador de conhecimento, ou seja, de utilidade prática para as pessoas.

Em [02], "história" recupera um memorável que remete a narrativas, a percepções, à produção de conhecimento e a processos de criação de identidade da humanidade, de grupos sociais e de indivíduos. Desse modo, há referência a percursos narrativos, a percepções, a criações e a transformações geradas pelos seres humanos como seres do(s) e no(s) mundo(s). É importante ressaltar que a temporalização do acontecimento, na perspectiva da Semântica do Acontecimento, não faz referência a fatos dispostos na linha cronológica do tempo (Cronos). Ela é uma temporalização singular, pois funda-se por um tempo linguístico próprio, autônomo e autossuficiente em relação ao sujeito empírico e ao cronos.

Nesse sentido, a designação "história" vincula-se a um memorável que relaciona os seres humanos à sua origem social e à sua dinâmica como espécie no e do mundo, com capacidade criadora e transformadora de si e do mundo.

A designação "história" também abre uma latência de futuro. Essa futuridade abre espaço para infinitas possibilidades de narrativas, de produção de conhecimento, de percepções, de criações e de transformações passíveis de serem realizadas por seres humanos, grupos ou indivíduos.

Enquanto futuridade, a designação "história" projeta a disciplina História como espaço que cria as condições espirituais, simbólicas e materiais necessárias para que os educandos compreendam as dinâmicas sócio-histórica da humanidade e percebam que cada ser humano é uma agente da sua própria história e da história da coletividade, pois "os homens fazem a sua 
própria história [...]”. (MARX, 2011, p. 25). No entanto, ser demiurgo da própria história não coloca a humanidade ou indivíduos sob o controle da história, pois, ainda segundo Marx (2011, p. 25), "[...] não a fazem de livre e espontânea vontade, pois não são eles quem escolhem as circunstâncias sob as quais ela é feita [...]". Essa é a história que tem sentido para os indivíduos e, em particular, para os educandos, a história viva, complexa e, às vezes, incompreensível.

No enunciado [02], à designação "história" rompe com a realidade do ensino de história vigente ainda na educação brasileira. Um modelo que privilegia a história enquanto elemento temporal linear e/ou cíclica, organizada em três grandes períodos: história antiga, história média e história moderna.

Para Koselleck (2014, p. 270-271):

Os livros escolares e os manuais ainda se baseiam nessa divisão tripla de toda a história. [...] para as histórias concretas e os grandes contextos, essas determinações temporais mostram-se demasiadamente formais e desprovidas de conteúdo. [...] as determinações temporais que destacam apenas três períodos são indefinidas demais para permitir uma divisão razoável da história real.

A partir da designação "história", no enunciado [02], é possível compreender a história como um constructo humano, realizado em diferentes extratos temporais e passível de ser reescrito, pois "o texto da história nunca está concluído e fixado" (KOSELLECK, 2014, p.115).

Segundo Koselleck (2014, p. 114-115), é preciso levar o aluno a considerar que:

[...] nunca seremos donos da história. Conhecemos apenas histórias, e, a fim de tornar possíveis as histórias, estamos sempre imersos nessas contraposições básicas inexoravelmente severas, que nos foram apresentadas: amigo e inimigo, secreto e público e todas essas outras categorias fundamentais cuja polaridade faz parte de toda "história".

Analisar-se-á agora a designação "tempo". Para tal, recortamos dois extratos textuais do LD de História em estudo.

Enunciado 03: "Vimos que cada povo possui uma cultura. Assim, com base em sua cultura, os povos criaram diferentes calendários, ou seja, diferentes modos de contar e dividir o tempo. Para dar início à contagem do tempo, cada povo escolheu uma data que é importante para ele. [...]." (BOULOS JUNIOR, 2015, p. 35).

Enunciado 04: "Ao longo do tempo, os seres humanos dominaram técnicas para produzir o fogo, inventaram as ferramentas, a agricultura, a escrita, o comércio, a cidade, a pintura, a música e, com isso, foram fazendo a História. Esse tempo resultante da ação dos seres humanos sobre a terra é chamado de tempo histórico. É, portanto, um tempo relacionado às experiências coletivas dos seres humanos, à história da humanidade" (BOULOS, 2015, p. 37).

É importante registrar que a nova cena enunciativa demostrada acima modifica a divisão do Locutor. Neste caso, tem-se um alocutor-x (pesquisador, autor) e um enunciador coletivo. Nos enunciados 03 e 04 o enunciador faz afirmações próprias de uma coletividade de pesquisadores de história.

Esclarecida a divisão do Locutor, passar-se-á à relação de DSD. No enunciado [03], a relação de Domínio Semântico de Determinação se estabelece de forma que "tempo" é determinado por calendário e por cultura, conforme demonstra o esquema abaixo.

DSD 3

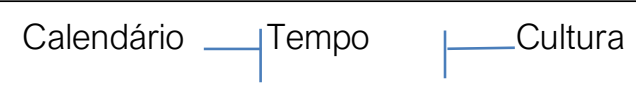




\section{$=\mathrm{T} R A M A=$}

Em [03], o sentido de "tempo" está relacionado à contagem e correlacionado a manifestações naturais (rotação da terra, manifestações climáticas, manifestações astronômicas etc.) e a manifestações mecânicas (os relógios, calendários etc.). Tempo significa período contínuo de caráter natural ou mecânico.

No enunciado [04], a relação de Domínio Semântico de Determinação se estabelece de forma que "tempo" é determinado pela experiência coletiva dos seres humanos (construção cultural), conforme demonstra o esquema abaixo.

DSD 4

Experiência coletiva dos seres humanos Tempo

No enunciado [04], a designação "tempo" refere-se à experiência coletiva da humanidade (tempo histórico).

No enunciado [03], "tempo" recupera um memorável que se refere a quantificável e mensurável em que os eventos históricos podem ser situados, conforme ilustrado nas figuras 1 e 2 abaixo.

Figura 1

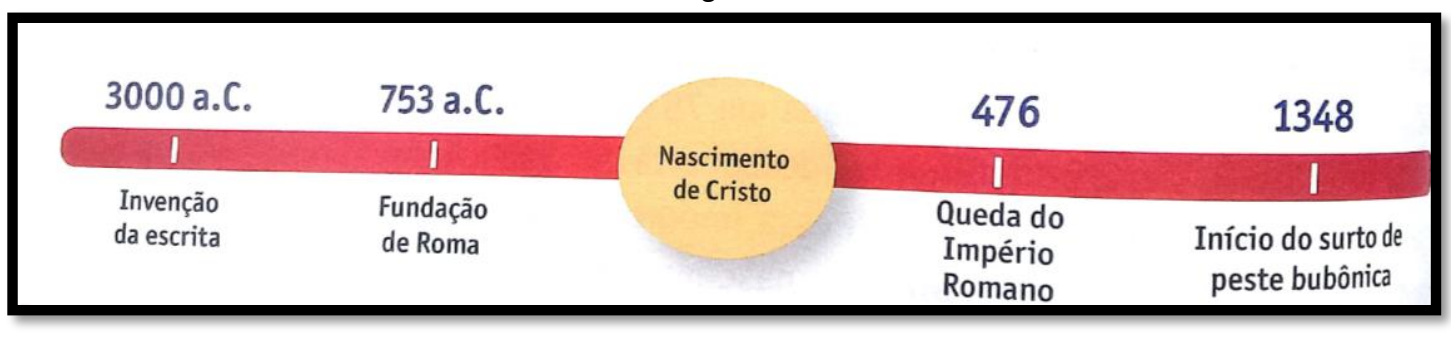

Fonte: História: sociedade \& cidadania

Figura 2

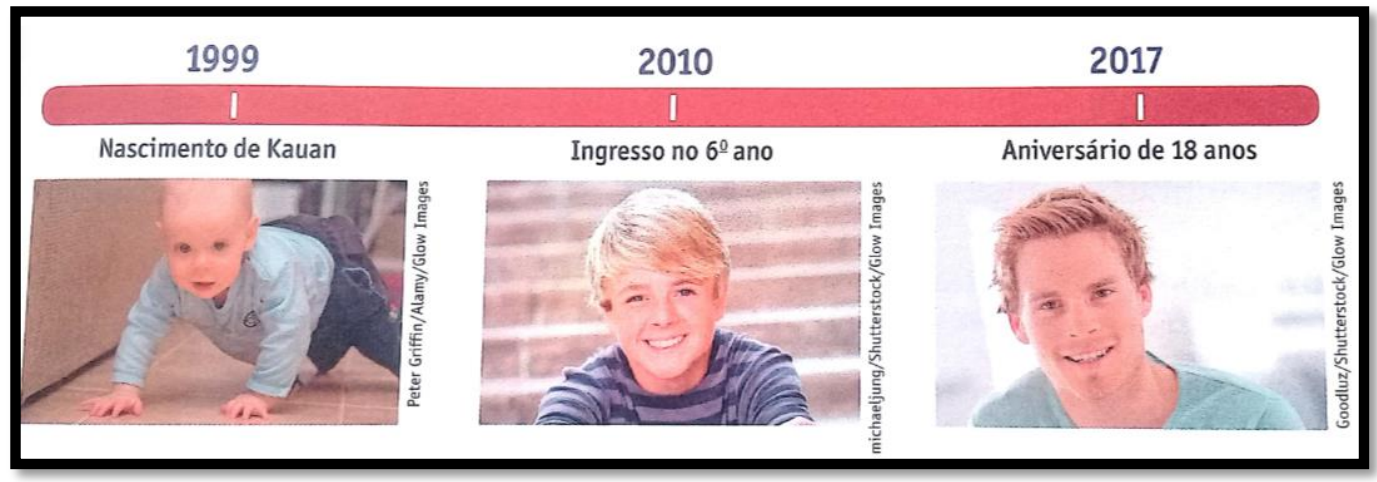

Fonte: História: sociedade \& cidadania

No enunciado [04], a designação "tempo" remete a um memorável que recupera o sentido de "tempo" como construção cultural, como uma construção humana que deve sempre levar em consideração a especificidade de cada época e que relaciona o conhecimento já acumulado, experienciado como passado, com as possibilidades que rompem em direção à futuridade. 


\section{$=\mathrm{T} R A M A=$}

\section{CONSIDERAÇÕES FINAIS}

A análise realizada revelou que a designação "história", no enunciado [01], significa fonte de desinteressante e obsolescência; no enunciado [02], significa dinamicidade, prazer e conhecimento. A designação "tempo", no enunciado [03], significa período contínuo de caráter natural e/ou mecânica; no enunciado [04], significa período contínuo de caráter coletivo (cultural).

No percurso desta pesquisa, confirmou-se a importância da integração da Semântica do Acontecimento ao ensino de História (interdisciplinaridade). Esta integração de áreas distintas, em particular História e Semântica do Acontecimento, amplia pedagogicamente as possibilidades de ensino, pois oferta aos professores outro instrumento didático-pedagógico que os auxilia no desenvolvimento do trabalho pedagógico em sala de aula. A semântica (fenômeno linguístico), como elemento didático-pedagógico integrada ao ensino de História, permite a apropriação dos sentidos das enunciações e possibilita a ampliação das condições de apropriação dos conteúdos em estudo por parte dos educandos. Vale registrar que a língua (escrita ou verbal) é o instrumento de interlocução entre seres humanos e entre seres humanos e o mudo. Ela não é o único instrumento de interlocução, mas certamente é um dos mais utilizados pela humanidade.

A língua é permeada de sentidos, e esses sentidos possibilitam a interação no mundo e com o mundo. Assim, apropriar-se da semântica para abordar os fenômenos da história é desnaturalizar a relação dos seres humanos com a língua e colocar a língua como elemento essencial na configuração das percepções do mundo. A semântica é, portanto, um elemento didático-pedagógico em sua essência.

A integração entre Semântica do Acontecimento e História, dessa forma, oferece aos alunos outras possibilidades de aprendizagem acerca da área aqui em estudo (história) e outras áreas (língua portuguesa). A abordagem do objeto de ensino sob a perspectiva da integração de áreas distintas possibilita aos alunos compreenderem o mundo a partir de sua complexidade, constituído de relações (des)integradoras, (des)estruturantes, contraditórias e até mesmo antagônicas.

A relação integrada entre Semântica do Acontecimento e História possibilita, ainda, o desenvolvimento da capacidade reflexiva dos alunos, pois thes permite observar que a compreensão da realidade social está diretamente relacionada com a perspectiva da qual se a observa. Essa forma de pensar o mundo é importante, pois permite aos alunos compreenderem que as relações sociais transcendem a visão reducionista, que enxerga o mundo sob a perspectiva do maniqueísmo.

\section{REFERÊNCIAS}

BENVENISTE, Émile. Problemas de linguística geral I. Campinas: Editora Pontes, 1976.

BENVENISTE, Émile. Problemas de linguística geral I. Campinas: Editora Pontes, 2005.

BENVENISTE, Émile. Problemas de linguística geral II. Campinas: Editora Pontes, 2006.

BOULOS JUNIOR, Alfredo. História sociedade \& cidadania, 6ªno. São Paulo, Editora FTD, 2015.

BRASIL. Ministério da Educação. Parâmetros Curriculares Nacionais. 2000.

BRASILSABIDO. População de João Pessoa-PB. 2010. Disponível em:

<http://www.brasilsabido.com.br/populacao/joao-pessoa-pb-4659.html>. Acesso em 30 de set. de 2018. BRÉAL, Michel. Ensaios semânticos. Campinas: Editora Educ.-Pontes, 1992.

DUCROT, Oswald. O dizer e o dito. Tradução Eduardo Guimarães. Campinas: Editora Pontes, 1987.

GUIMARÃES, Eduardo. Semântica, enunciação e sentido. Campinas: Editoras Pontes, 2018.

GUIMARÃES, Eduardo. Semântica do acontecimento: um estudo enunciativo da designação. Campinas:

Editora Pontes, 2005.

KOSELLECK, Reinhart. Estratos do tempo: estudos sobre história. Tradução Markus Hediger. Rio de Janeiro, Editora Contraponto-PUC Rio, 2014.

LYONS, John. Linguagem e linguística: uma introdução. Tradução Marilda Winkler Averbug. Rio de Janeiro: Editora Zahar, 1982. 
MARX, Karl. O 18 de brumário de Luís Bonaparte. Tradução Nélio Schneider. São Paulo: Editora Boitempo, 2011.

MARX, Karl. O Capital: crítica da economia política. Livro I. Tradução Rubens Enderle. São Paulo: Editora Boitempo, 2013.

NASCIMENTO, Erivaldo Pereira do. Jogando com as vozes do outro: a polifonia - recurso modalizador - na notícia jornalística. 239 folhas. Tese de Doutorado (Doutorado em Linguística) - Universidade Federal da Paraíba, Paraíba, João Pessoa, 2005.

PIMENTA, Selma Garrido. Questões sobre a organização do trabalho escolar. Disponível em:

PIMENTA_S._G._Quest_es_sobre_a_organiza_o_do_trabalho_na_escola (1). Pdf-Adobe Acrobat Reader DC. Acesso em 04 de fev. de 2019.

RANCIĖRE, Jacques. O desentendimento: política e filosofia. Tradução Ângela Leite Lopes. São Paulo: Editora 34, 2018.

RANCIĖRE, Jacques. Política da escrita. Tradução Raquel Ramalhete et al. São Paulo: Editora 34, 2017.

SAVIANI, Dermeval. História do tempo e tempo da história: estudos de historiografia e história da educação.

Campinas, SP: Autores Associados, 2015.

SECRETARIA DE EDUCAÇÃO E CULTURA DO MUNICIÍPIO DE JOÃO PESSOA. Relação das escolas

municipais. Disponível em: <http://www.joaopessoa.pb.gov.br/secretarias/sedec/escolas-municipais/>. Acesso em 20 de fev. de 2018.

SILVA, Antônio Marcos. Argumentação e polifonia na língua. In. A argumentação na redação comercial e oficial: estratégias semântico-discursivas em gêneros formulaicos. Organização Erivaldo Pereira do Nascimento. João Pessoa: Editora da UFPB, 2012.

TONET, Ivo. Método científico: uma abordagem ontológica. São Paulo: Editora Instituto Lukács, 2013.

Enviado em 26-08-2020

Revisões Requeridas em 31-10-2020

Aceito em $06-11-2020$ 